\title{
Individually shortened duration versus standard duration of elastic compression therapy for prevention of post-thrombotic syndrome
}

Citation for published version (APA):

Amin, E. E., ten Cate-Hoek, A. J., Bouman, A. C., Meijer, K., Tick, L., Middeldorp, S., Mostard, G., ten Wolde, M., van den Heiligenberg, S., van Wissen, S., van de Poet, M., Villalta, S., Serne, E., Otten, H. M., Klappe, E., Prandoni, P., Prins, M. H., ten Cate, H., \& Joore, M. A. (2018). Individually shortened duration versus standard duration of elastic compression therapy for prevention of post-thrombotic syndrome: a cost-effectiveness analysis. The Lancet Haematology, 5(11), E512-E519. https://doi.org/10.1016/S23523026(18)30151-0

Document status and date:

Published: 01/11/2018

DOI:

10.1016/S2352-3026(18)30151-0

Document Version:

Publisher's PDF, also known as Version of record

Document license:

Taverne

Please check the document version of this publication:

- A submitted manuscript is the version of the article upon submission and before peer-review. There can be important differences between the submitted version and the official published version of record.

People interested in the research are advised to contact the author for the final version of the publication, or visit the DOI to the publisher's website.

- The final author version and the galley proof are versions of the publication after peer review.

- The final published version features the final layout of the paper including the volume, issue and page numbers.

Link to publication

\footnotetext{
General rights rights.

- You may freely distribute the URL identifying the publication in the public portal. please follow below link for the End User Agreement:

www.umlib.nl/taverne-license

Take down policy

If you believe that this document breaches copyright please contact us at:

repository@maastrichtuniversity.nl

providing details and we will investigate your claim.
}

Copyright and moral rights for the publications made accessible in the public portal are retained by the authors and/or other copyright owners and it is a condition of accessing publications that users recognise and abide by the legal requirements associated with these

- Users may download and print one copy of any publication from the public portal for the purpose of private study or research.

- You may not further distribute the material or use it for any profit-making activity or commercial gain

If the publication is distributed under the terms of Article $25 \mathrm{fa}$ of the Dutch Copyright Act, indicated by the "Taverne" license above, 


\title{
Individually shortened duration versus standard duration of elastic compression therapy for prevention of post-thrombotic syndrome: a cost-effectiveness analysis
}

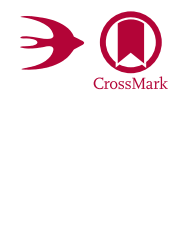

\begin{abstract}
Elham E Amin, Arina J ten Cate-Hoek, Annemieke C Bouman, Karina Meijer, Lidwine Tick, Saskia Middeldorp, Guy Mostard, Marije ten Wolde, Simone van den Heiligenberg, Sanne van Wissen, Marlene van de Poel, Sabina Villalta, Erik Serné, Hans Martin Otten, Edith Klappe,

Paolo Prandoni, Martin H Prins, Hugo ten Cate, Manuela A Joore
\end{abstract}

\section{Summary}

Background The IDEAL DVT study showed that it was safe to shorten the duration of elastic compression therapy on an individualised basis after deep vein thrombosis for prevention of post-thrombotic syndrome. In this study, we assessed the cost-effectiveness of this strategy.

Methods IDEAL DVT was a multicentre, randomised, non-inferiority trial that included patients with acute proximal deep vein thrombosis of the leg. After 6 months of elastic compression therapy, patients were randomly assigned (1:1) to the standard 2 years of elastic stocking compression therapy or shortened duration of compression therapy based on the patient's Villalta score. For our cost-effectiveness analysis, we assessed quality-adjusted life-years (QALYs), measured with the three-level version of EQ-5D (EQ-5D-3L; Dutch and UK tariff) and the 36-item Short Form Health Survey (SF-36), and costs in $€$ (health-care and societal perspective) according to the intention-to-treat approach. Data were collected at $3,6,12$, and 24 months after diagnosis of thrombosis. We calculated incremental net monetary benefit using a QALY threshold of $€ 30000$, and obtained bootstrapped means and $95 \%$ CIs. IDEAL DVT is registered with ClinicalTrials.gov, number NCT01429714.

Findings Between March 22, 2011, and July 1, 2015, 865 patients were enrolled in IDEAL DVT. 437 were assigned to individualised duration of elastic compression therapy and 428 to standard duration of elastic compression therapy. Nine patients were eventually excluded because of recurrent venous thromboembolism within 6 months after the first event. From a societal perspective, for every QALY lost measured with the EQ-5D Dutch tariff, cost savings were $€ 305.992$ (incremental net monetary benefit $€ 3205$, 95\% CI 502-5741), and for every QALY lost based on the Short-Form Six-Dimension (SF-6D) utility score (derived from SF-36), cost savings were $€ 6030.941$ (€3540, 95\% CI 1174-5953). Using the UK tariff for EQ-5D, the individualised strategy was more effective and less costly (€4071, 1452-6647). The probability that the individualised strategy was cost-effective was $99 \%$ at a threshold of $€ 30000$ per QALY (EQ-5D Dutch tariff).

Interpretation Individually shortened duration of elastic compression therapy was cost-effective compared with standard duration elastic compression therapy. Use of an individualised approach to elastic stocking compression therapy for the prevention of post-thrombotic syndrome after deep vein thrombosis could lead to substantial costs savings without loss in health-related quality of life.

Funding Netherlands Organisation for Health Research and Development.

Copyright (C) 2018 Elsevier Ltd. All rights reserved.

\section{Introduction}

Post-thrombotic syndrome is a long-term consequence of deep vein thrombosis. $20-50 \%$ of patients diagnosed with deep vein thrombosis develop post-thrombotic syndrome within 2 years after diagnosis of a deep vein thrombus in the leg. ${ }^{1}$ The syndrome is irreversible and characterised by oedema, skin changes - which can range from mild skin signs to venous ulcers-and leg complaints. ${ }^{2,3}$ Post-thrombotic syndrome is associated with disability and decreased quality of life. As severity increases, quality of life worsens. ${ }^{4}$ Furthermore, postthrombotic syndrome is associated with substantial economic costs. ${ }^{5,6}$
To prevent post-thrombotic syndrome, all patients with thrombosis of the leg are advised to wear elastic compression stockings for 2 years. ${ }^{7-9}$ A Cochrane metaanalysis ${ }^{10}$ found that compression therapy caused a $30 \%$ reduction in the occurrence of post-thrombotic syndrome. However, costs of the use of elastic compression stockings are not negligible. In the Netherlands alone, the cost of stockings for prevention of post-thrombotic syndrome was estimated to be $€ 2 \cdot 5$ million per year. ${ }^{11}$ Not all patients can apply and remove the stockings independently; in the Netherlands, $€ 21$ million is needed for home care to assist patients with the application of stockings. ${ }^{12-14}$ Hence, if the duration of elastic compression
Lancet Haematol 2018,

5: e512-19

Published Online October 9, 2018 http://dx.doi.org/10.1016 S2352-3026(18)30151-0 See Comment page e494 Department of Biochemistry, Cardiovascular Research Institute Maastricht (EEAmin MD, A J ten Cate-Hoek MD, ACBouman MD Prof $\mathrm{H}$ ten (ate MD) and Department of Clinical Epidemiology and Medical Technology Assessment School for Public Health and Primary Care (E E Amin, A C Bouman, Prof M H Prins MD Prof M A Joore MD), Maastricht University, Maastricht, Netherlands; Department of Internal Medicine, Maastricht University Medical Centre, Maastricht, Netherlands (E E Amin, A J ten Cate-Hoek, A C Bouman, Prof H ten Cate); Department of Haematology, University Medical Centre Groningen, Groningen, Netherlands (Prof K Meijer MD); Department of Internal Medicine, Maxima Medical Centre Eindhoven, Eindhoven, Netherlands (L Tick MD); Department of Internal Medicine, Academic Medical Centre Amsterdam, Amsterdam, Netherlands (Prof S Middeldorp MD); Department of Internal Medicine, Zuyderland Medical Centre, Heerlen, Netherlands (G Mostard MD); Department of Internal Medicine, Flevoziekenhuis, Almere, Netherlands ( $M$ ten Wolde MD); Department of Internal Medicine, Westfriesgasthuis, Hoorn, Netherlands (S van den Heiligenberg MD); Department of Internal Medicine, Onze Lieve Vrouwe Gasthuis, Amsterdam Netherlands 


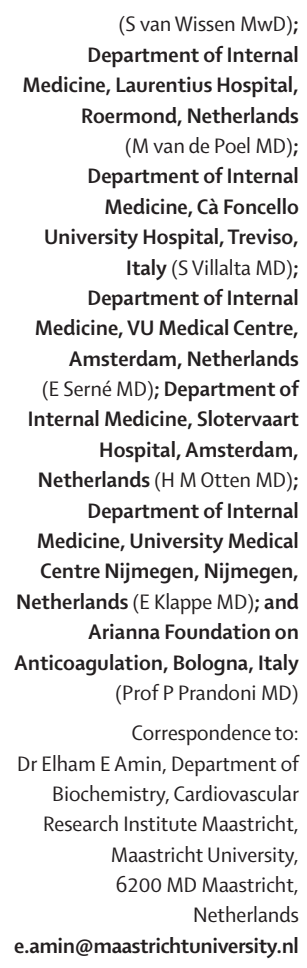

(S van Wissen MwD);

ine, Laurentius Hospital

(Mvand, Netherlands

Department of Internal

Medicine, Cà Foncello

rsity Hospital, Treviso,

Department of Internal

Medicine, VU Medical Centre,

(E Serné MD); Department of

Internal Medicine, Slotervaart

spital, Amsterdam,

(HMOten MD);

edicine, University Medical

Centre Nijmegen, Nijmegen,

Netherlands (E Klappe MD); and

ulation, Bologna, Italy

(Prof P Prandoni MD)

Correspondence to:

Dr Elham E Amin, Department of

Biochemistry, Cardiovascular

Institute Maastricht,

Netherlands

e.amin@maastrichtuniversity.nl

\section{Research in context}

\section{Evidence before this study}

We did a systematic literature review in April, 2018.

We searched MEDLINE, the Current Controlled Trials database, the UK National Health Service Centre for Reviews and Dissemination database, and the Health Economic Evaluation database for any type of article, with no date or language restrictions, using the search terms ("post thrombotic syndrome" OR "post phlebitic syndrome") AND "compression therapy" AND "cost". When including the term "cost" we found no results. When excluding the term "cost", we found two studies that reported on variable duration of compression therapy. One trial from 2008 compared treatment with 6 months of elastic compression therapy with a prolonged duration of 24 months and showed no difference between groups in post-thrombotic skin changes assessed according to the Clinical, Etiological, Anatomical, Pathophysiologic score. The OCTAVIA study compared standard 24 months of elastic compression therapy with 1 year of compression therapy in selected patients with Villalta scores of less than 5 and excellent adherence to compression therapy, and did not show non-inferiority for the shortened duration of therapy. In December, 2017, we reported the primary outcome of the IDEAL DVT study showing that individualised shortened duration of elastic compression therapy for prevention of post-thrombotic syndrome was feasible and was not associated with significant differences between groups in the proportion of patients with post-thrombotic syndrome after 2 years. We concluded that individualised duration of elastic compression therapy was safe and effective and was likely to reduce health-care costs.

\section{Added value of this study}

To our knowledge, this analysis of IDEAL DVT is the first to assess the cost-effectiveness of an individualised shortened duration of elastic compression therapy compared with standard 2-year duration. We found the individualised strategy to be cost-effective. Because most patients who develop post-thrombotic syndrome are diagnosed in the first 2 years after diagnosis of deep vein thrombosis, we assumed that this timeframe would be sufficient to capture the most important differences in costs and health effects. In a subgroup analysis we assessed the cost-effectiveness of shortened duration of elastic compression therapy in a subset of patients with low Villalta scores $(<5)$ at 6 months compared with a similar selection of patients within the standard treatment group. We found that despite slightly more occurrences of post-thrombotic syndrome in the group with individualised shortened treatment duration, for this subgroup of patients the individualised strategy was cost-effective.

Implications of all the available evidence

We showed that by using an individualised approach, substantial cost savings can be made, both from a health-care perspective and a societal perspective, without significant loss in health-related quality of life. Therefore, individualised compression therapy should be embedded in current guidelines and implemented in daily practice. stocking treatment could be shortened in patients for whom it is safe to do so, a substantial burden to patients and society could be saved.

The IDEAL DVT study ${ }^{15}$ investigated individualised versus standard duration of elastic compression therapy for prevention of post-thrombotic syndrome. Most patients in the individualised group were able to stop treatment early; 236 (55\%) of 432 patients wore the stockings for only 6 months. No significant difference between groups was reported in the proportion of patients with post-thrombotic syndrome at 24 months (odds ratio $1 \cdot 06$, 95\% CI 0.78-1.44). However, a post-hoc analysis of 420 patients without symptoms at 1 year after diagnosis of thrombosis and with excellent adherence to therapy showed increased incidence of mild postthrombotic syndrome in patients who stopped stocking treatment early on the basis of the International Society on Thrombosis scoring method for the Villalta score (risk ratio $1 \cdot 6,95 \% \mathrm{CI} 1 \cdot 2-2 \cdot 3$ ).

To our knowledge, only two other studies have assessed variable duration of elastic compression therapy to prevent post-thrombotic syndrome, ${ }^{16,17}$ but neither assessed the cost-effectiveness of such strategies.

We report a health economic evaluation of the IDEAL DVT study. We assessed the cost-effectiveness of individualised duration of elastic compression therapy compared with standard duration, both from a health-care perspective and from a societal perspective. Additionally, we assessed whether it was cost-effective to provide patients with mild post-thrombotic syndrome-as identified by a post-hoc analysis - with prolonged compression therapy.

\section{Methods}

\section{Study design and participants in IDEAL DVT}

The IDEAL DVT study, a multicentre, randomised, singleblind, allocation-concealed, non-inferiority trial, was done at 12 hospitals in the Netherlands and two hospitals in Italy. ${ }^{15}$ Patients with acute proximal deep vein thrombosis of the leg, without pre-existing venous insufficiency (Clinical Etiological Anatomical and Pathophysiologic [CEAP] score $<\mathrm{C} 3$ ), were randomly assigned (1:1) to individualised duration of elastic compression therapy or to standard duration compression therapy for 2 years. Randomisation was done with a web-based automatic randomisation programme (TENALEA) with a random block size (2-12), and was stratified by centre, age, and body-mass index. All patients wore elastic compression stockings for the first 6 months after diagnosis of deep vein thrombosis. After 6 months, the duration of further use of elastic compression stockings in patients in the 
individualised treatment group depended on the patient's signs and symptoms assessed with the Villalta score. Patients who were assigned to standard duration of stocking therapy were instructed to wear elastic compression stockings for the entire 2-year duration of the study. Follow-up visits in the study were at 3, 6, 12, and 24 months after diagnosis of deep vein thrombosis. 865 patients were enrolled between March 22, 2011, and July 1, 2015; 437 were assigned to individualised duration and 428 to standard duration of treatment. ${ }^{15}$ The primary endpoint of IDEAL DVT was post-thrombotic syndrome at 24 months. IDEAL DVT is registered with ClinicalTrials. gov, number NCT01429714.

\section{Data inputs}

For our cost-effectiveness analysis, we used data on utilities (health-related quality of life weights), resource use, and productivity from the IDEAL DVT trial. ${ }^{11}$ In the trial, ${ }^{11}$ at a one-sided significance level of $5 \%$ and a power of $80 \%$, a sample size of 848 was required to test the hypothesis on the basis of an expected incidence of postthrombotic syndrome of $20-30 \%$. Loss to follow-up was expected to be less than $2 \%$, thus a sample of 864 was needed. Costs and utilities were collected prospectively for every patient at $3,6,12$, and 24 months after diagnosis of acute deep vein thrombosis. In cases of recurrent ipsilateral thrombosis within the first 6 months after diagnosis, patients were excluded from further assessment.

Utilities were measured with the three-level version of EQ-5D (EQ-5D-3L) and the 36-item Short Form Health Survey (SF-36) version 2. ${ }^{18-20}$ Patients received a link by email to an online questionnaire. Patients that did not have internet received a paper version via mail. The questionnaires were completed the day before the clinic visit. EQ-5D-3L is made up of five questions with three options (no, moderate, or severe problems) regarding five dimensions of general health status (mobility, self-care, usual activity, pain, and anxiety). For calculation of utilities from EQ-5D-3L scores, we used both the Dutch tariff and the UK tariff. ${ }^{21,22}$ SF-36 consists of 36 questions regarding the health domains of physical functioning, physical role functioning, emotional role functioning, social role functioning, mental health, bodily pain, vitality, and general health perceptions. From SF-36 scores, we derived the Short-Form Six-Dimension (SF-6D) utility score. ${ }^{23}$

For the purposes of this study we developed a cost questionnaire containing items to assess use of healthcare resources (general practitioner, medical specialist, anticoagulation clinic, physiotherapist, need for home care, use of elastic compression stockings, and medication use), patient costs (travel costs to medical facilities), and indirect costs (work productivity loss) related to leg complaints. For work productivity loss, we applied the prospective modular Productivity and Disease Questionnaire. ${ }^{24}$ This questionnaire used a recall period of 3 months. The guideline on health economic evaluation drafted by the Netherlands Health Care Institute was used for the standard unit price for the items in each cost category. ${ }^{25}$ We calculated the costs related to work productivity loss using the friction cost method as recommended in the Netherlands. ${ }^{26}$ The friction cost method takes the employer's perspective and only counts the costs of work productivity lost until another employee takes over the patient's work, assuming that long-term absentees are replaced. ${ }^{26}$ The current friction period is set to 12 weeks in the Dutch health economic guideline. ${ }^{25}$ All reported costs were in $€$ at 2015 price levels.

\section{Economic evaluation}

The outcome for the economic evaluation was qualityadjusted life-years (QALYs). A QALY combines mortality and quality of life into a single index, multiplying time by utility. 1 QALY represents 1 life-year in perfect health. Hence, in this analysis a patient could experience a maximum of 2 QALYs. We derived QALYs from utilities on the basis of EQ-5D-3L (Dutch and UK tariffs) and SF-6D scores. Because the intervention only started at 6 months after enrolment of each patient, we used the group average (ie, mean) for the calculation of QALY in the first 6 months. After 6 months, we assumed for each patient that the utility between two consecutive measurements would equal the mean of those two measurements.

Because the cost questionnaire had a 3-month recall period, we interpolated the costs. Similar to the analysis of QALYs, we also used the group mean for the costs in the first 6 months for each patient. Subsequently, for each patient, we multiplied the costs reported at 12 months by 2 and the mean of the costs reported at 12 and 24 months by 4 . We calculated health-care costs and societal costs. Societal costs consist of health-care and patient and family costs, and costs associated with lost productivity.

We determined cost-effectiveness by relating the incremental costs to the incremental QALYs over the 2-year time horizon. Additionally, we calculated incremental net monetary benefits by multiplying incremental QALYs by the customary threshold of $€ 30000$ and subtracting the incremental costs. A positive incremental net monetary benefit indicates cost-effectiveness.

\section{Ethics approval}

Ethics approval was obtained from the institutional review board of Maastricht University Medical Centre (Maastricht, Netherlands; number 32073.068.10) and was ratified by the ethical review board of the participating centres. All participants gave written informed consent before any study-related activity was done.

\section{Statistical analysis}

We used the intention-to-treat approach for data analysis. We imputed missing data with single stochastic regression imputation, using chained equations to 
prevent loss of statistical power and to decrease the probability of obtaining biased estimates. We assumed data were missing at random (ie, missing conditional on other covariates). We used predictive mean matching to draw the imputed values, because this method is more robust to misspecification of the imputation model and non-normality of continuous variables compared with standard regression imputation. ${ }^{27}$ We assessed group comparability for differences in demographic and clinical characteristics, both for differences in QALYs and for costs. We assessed differences in demographic and clinical characteristics with an independent sample $t$ test or Mann-Whitney $U$ test depending on the normality of data distribution, and for categorical variables we used $\chi^{2}$. We tested differences in quality of life over time with split plot ANOVA analysis. We used bootstrapping to obtain 95\% CIs for QALYs, costs, and incremental net monetary benefits. In this method, cost and effectiveness (QALYs) pairs are randomly drawn from the original data with replacement until the size of the original sample is achieved. We drew 5000 bootstrap samples to obtain a stable result. We presented the results of the bootstrap simulation in a cost-effectiveness plane in which the incremental costs were plotted against incremental QALYs. We obtained CIs based on the 2.5th and 97.5th percentiles. We obtained cost-effectiveness acceptability curves to determine the probability of costeffectiveness for individualised duration of elastic compression stockings versus standard duration of stockings for different thresholds for a QALY. Because

\begin{tabular}{|c|c|c|c|}
\hline & $\begin{array}{l}\text { Individualised duration of } \\
\text { compression stocking use } \\
(n=432)\end{array}$ & $\begin{array}{l}\text { Standard 2-year duration } \\
\text { of compression stocking } \\
\text { use }(n=424)\end{array}$ & $p$ value \\
\hline EQ-5D Dutch tariff & .. & .. & $0 \cdot 26$ \\
\hline 3 months & $0.8717(0.2063)$ & $0.8739(0.1986)$ & .. \\
\hline 6 months & $0.8903(0.1932)$ & $0.8852(0.1774)$ & .. \\
\hline 12 months & $0.8720(0.2319)$ & $0.8752(0.2069)$ & .. \\
\hline 24 months & $0.8640(0.2691)$ & $0.8848(0.1974)$ & .. \\
\hline EQ-5D UK tariff & .. & .. & $0 \cdot 36$ \\
\hline 3 months & $0.8524(0.2220)$ & $0.8541(0.2235)$ & .. \\
\hline 6 months & $0.8873(0.1839)$ & $0.8658(0.1995)$ & .. \\
\hline 12 months & $0.8748(0.2060)$ & $0.8639(0.2182)$ & .. \\
\hline 24 months & $0.8877(0.2191)$ & $0.8809(0.1936)$ & .. \\
\hline SF-6D & .. & .. & $0 \cdot 38$ \\
\hline 3 months & $0.6258(0.0560)$ & $0.6295(0.0552)$ & .. \\
\hline 6 months & $0.7963(0.1252)$ & $0.7887(0.1279)$ & .. \\
\hline 12 months & $0.8055(0.1268)$ & $0.8093(0.1266)$ & .. \\
\hline 24 months & $0.8093(0.1326)$ & $0.8082(0.1355)$ &.. \\
\hline \multicolumn{4}{|l|}{ QALYs over 2 years' time horizon } \\
\hline Based on EQ-5D Dutch tariff & $1.7487(0.3223)$ & $1.7602(0.2509)$ & $0 \cdot 38$ \\
\hline Based on EQ-5D UK tariff & $1.7543(0.2746)$ & $1.7373(0.2651)$ & $0 \cdot 51$ \\
\hline Based on SF-6D & $1.5628(0.1747)$ & $1.5633(0.1773)$ & 0.22 \\
\hline
\end{tabular}

the study predominantly investigated Dutch patients, we considered analysis with the QALY based on the EQ-5D-3L Dutch tariff as the base case. We did sensitivity analyses with QALYs based on the more widely used EQ-5D-3L UK tariff (to increase generalisability of our results and hence usefulness for other countries) and the SF-6D.

We did two additional analyses: a sensitivity analysis with complete cases (ie, without missing data), and a subgroup analysis in a subset of patients with low Villalta scores who stopped treatment at 6 months compared with patients with similar Villalta scores within the standard treatment group who continued stocking therapy until the end of study.

Analyses were done in SPSS version 23 and Excel version 10.

\section{Role of the funding source}

The funder of the study had no role in study design, data collection, data analysis, data interpretation, or writing of the report. All authors had full access to all the data in the study and AJtC-H and MAJ had final responsibility for the decision to submit for publication.

\section{Results}

Between March 22, 2011, and July 1, 2015, 865 patients were enrolled in the study. 437 were randomly assigned to individualised duration of elastic compression therapy and 428 to standard duration of elastic compression therapy. Nine patients were eventually excluded because of recurrent venous thromboembolism within 6 months after the first event. Before imputation, the proportion of missing EQ-5D questionnaires was 68 (8\%) of 856 at 3 months, 95 (11\%) of 856 at 6 months, 134 (16\%) of 856 at 12 months, and 198 (23\%) of 856 at 24 months. For the SF-6D and cost questionnaires, these proportions were 139 (16\%) of 856 at 3 months, 154 (18\%) of 856 at 6 months, $194(23 \%)$ of 856 at 12 months, and 259 (30\%) of 856 at 24 months.

We found no statistically significant differences between the group utilities at any timepoint (table 1). QALYs based on the EQ-5D-3L Dutch tariff were 1.7487 (SD 0.3223, 95\% CI 1.7177-1.7778) for individualised duration of therapy and $1.7602(0.2509,1.7355-1.7831)$ for standard duration of therapy. With the SF-6D, QALYs were $1.5628(0 \cdot 1747,1 \cdot 5458-1.5788)$ for individualised duration of therapy and $1.5633(0.1773,1.5462-1.5801)$ for standard duration of therapy. QALYs based on the EQ-5D-3L UK tariff were $1.7543(0 \cdot 2746,1 \cdot 7273-1 \cdot 7790)$ for individualised duration of therapy and $1.7373(0 \cdot 2651$, $1 \cdot 7110-1 \cdot 7619)$ for standard duration of therapy.

The mean societal costs were lower for individualised duration of compression therapy (€8251, 95\% CI 6690 to 9690) compared with standard duration of therapy (€11803, 10020 to 13651 ; table 2). The incremental societal costs amounted to $-€ 3552$ (95\% CI -5793 to -1241 ; table 2). In both the individualised duration of 


\begin{tabular}{|c|c|c|c|c|c|c|c|c|c|}
\hline & \multicolumn{3}{|c|}{ Individualised duration of stocking use $(n=432)$} & \multicolumn{3}{|c|}{ Standard 2 year duration of stocking use $(n=424)$} & \multirow{2}{*}{$\begin{array}{l}\text { Incremental } \\
\text { health-care } \\
\text { cost, } €\end{array}$} & \multirow{2}{*}{$\begin{array}{l}\text { Incremental } \\
\text { patient, family, } \\
\text { and indirect cost, } €\end{array}$} & \multirow{2}{*}{$\begin{array}{l}\text { Incremental } \\
\text { total societal } \\
\text { cost, } €\end{array}$} \\
\hline & $\begin{array}{l}\text { Mean } \\
\text { health-care } \\
\text { cost } €\end{array}$ & $\begin{array}{l}\text { Mean patient, } \\
\text { family, and } \\
\text { indirect cost, } €\end{array}$ & $\begin{array}{l}\text { Mean total } \\
\text { societal cost, } €\end{array}$ & $\begin{array}{l}\text { Mean health- } \\
\text { care cost, } €\end{array}$ & $\begin{array}{l}\text { Mean patient, } \\
\text { family, and } \\
\text { indirect cost, } €\end{array}$ & $\begin{array}{l}\text { Mean total } \\
\text { societal cost, } €\end{array}$ & & & \\
\hline \multicolumn{10}{|l|}{ Visit } \\
\hline 3 months & 1203 & 901 & 2108 & 926 & 997 & 1926 & 277 & -96 & 182 \\
\hline 6 months & 602 & 705 & 1307 & 954 & 547 & 1501 & -352 & 158 & -194 \\
\hline 12 months & 671 & 199 & 870 & 1765 & 253 & 2018 & -1094 & -55 & -1148 \\
\hline 24 months & 1213 & 227 & 1440 & 887 & 29 & 916 & 326 & 198 & 524 \\
\hline $\begin{array}{l}\text { Total overall costs } \\
\text { over } 2 \text { years }\end{array}$ & 6027 & 2233 & 8259 & 9754 & 2042 & 11796 & -3727 & 191 & -3536 \\
\hline $\begin{array}{l}\text { Total overall costs over } \\
2 \text { years, bootstrapped } \\
\text { mean }(95 \% \mathrm{Cl})\end{array}$ & $\begin{array}{l}6022 \text { (5003 to } \\
7061)\end{array}$ & $\begin{array}{l}2245 \text { (1465 to } \\
3235)\end{array}$ & $\begin{array}{l}8251 \text { (6990 to } \\
9690)\end{array}$ & $\begin{array}{l}9740 \text { (8054 to } \\
11561)\end{array}$ & $\begin{array}{l}2052 \text { (1582 to } \\
2575)\end{array}$ & $\begin{array}{l}11803 \text { (10 } 020 \text { to } \\
13651)\end{array}$ & $\begin{array}{l}-3718(-5802 \text { to } \\
-1740)\end{array}$ & 193 (-757 to 1242) & $\begin{array}{l}-3552(-5793 \\
\text { to }-1241)\end{array}$ \\
\hline
\end{tabular}

therapy and the standard duration of therapy groups, the mean societal costs mainly consisted of health-care costs (€6022 [95\% CI 5003 to 7061] for individualised duration, and $€ 9740$ [8054 to 11561] for standard duration; table 3). Health-care costs were mostly for home care (€4417.01 for individualised duration and $€ 7438.60$ for standard duration; table 3). Patient and family and productivity costs were slightly lower for individualised duration of stockings as compared with standard duration (€563 [95\% CI 426 to 779] vs €601 [485 to 749]; table 3).

The mean incremental cost-effectiveness ratio in the base case equalled €305.992 saved per QALY lost with the EQ-5D-3L Dutch tariff (table 4). When QALYs were based on the SF-6D, the mean incremental costeffectiveness ratio was €6030.941 saved per QALY lost (table 4). With the EQ-5D-3L UK tariff, the intervention was found to be more effective and cost saving (table 4). The incremental net monetary benefit in the base case was $€ 3205$ (95\% CI 502-5741) with the EQ-5D-3L Dutch tariff, €4071 (1452-6647) with the EQ-5D-3L UK tariff, and $€ 3540$ (1174-5953) with SF-6D. The uncertainty surrounding the incremental costs and QALYs is shown in figure 1 . The probability for the individualised strategy to be cost-effective was $99 \%$ at a threshold of $€ 30000$ per QALY (on the basis of the EQ-5D-3L Dutch tariff; figure 2). The probability that the study was cost-effective at thresholds between $€ 7000$ and $€ 82000$ was $90 \%$ at the lowest (figure 2). Complete case analysis showed that individualised shortened duration of compression therapy was more effective and cost saving compared with standard duration of compression therapy, irrespective of the instrument used to assess utilities for QALYs.

We compared the cost-effectiveness of shortened duration of therapy in the individualised intervention group for a subgroup patients who did not wear elastic compression stockings after 6 months compared with patients in the standard duration group who had similar

\begin{tabular}{|c|c|c|c|c|c|}
\hline & \multirow[t]{2}{*}{ Unit cost, $€$} & \multicolumn{2}{|c|}{$\begin{array}{l}\text { Individualised duration of } \\
\text { stocking use }(n=432)\end{array}$} & \multicolumn{2}{|c|}{$\begin{array}{l}\text { Standard 2-year duration } \\
\text { of stocking use }(n=424)\end{array}$} \\
\hline & & $\begin{array}{l}\text { Number } \\
\text { of users }\end{array}$ & Mean cost, $€$ & $\begin{array}{l}\text { Number } \\
\text { of users }\end{array}$ & Mean cost, $€$ \\
\hline \multicolumn{6}{|l|}{ Health-care costs } \\
\hline General practitioner & $33-50$ & 94 & $188 \cdot 27$ & 107 & 200.66 \\
\hline $\begin{array}{l}\text { General practitioner out of } \\
\text { hours care }\end{array}$ & $33-50$ & 13 & 36.87 & 13 & 76.03 \\
\hline Medical specialist & 91 & 139 & $494 \cdot 85$ & 145 & $537 \cdot 70$ \\
\hline Medication use & $1 \cdot 07-74 \cdot 78$ & 432 & $92 \cdot 55$ & 424 & $150 \cdot 12$ \\
\hline Anticoagulation clinic & 9 & 316 & 178.93 & 299 & $227 \cdot 60$ \\
\hline Elastic compression stockings* & 50 & $432^{*}$ & $127 \cdot 30$ & 424 & $339 \cdot 28$ \\
\hline Physiotherapy & $33-50$ & 50 & $491 \cdot 30$ & 48 & 783.87 \\
\hline Home care & $23-73$ & 76 & $4417 \cdot 01$ & 62 & 7438.60 \\
\hline $\begin{array}{l}\text { Total health-care costs } \\
\text { bootstrapped mean }(95 \% \mathrm{Cl})\end{array}$ &.. &.. & $\begin{array}{l}6022 \\
(5003-7061)\end{array}$ &. & $\begin{array}{l}9740 \\
(8054-11561)\end{array}$ \\
\hline \multicolumn{6}{|l|}{ Patient and family costs } \\
\hline Travel costs & $2 \cdot 66-43 \cdot 14$ & 55 & 88.03 & 55 & $80 \cdot 53$ \\
\hline Family care & 14 & 74 & 476.94 & 68 & 518.82 \\
\hline $\begin{array}{l}\text { Total patient and family costs, } \\
\text { bootstrapped mean }(95 \% \mathrm{Cl})\end{array}$ &.. &.. & $\begin{array}{l}563 \\
(426-779)\end{array}$ &.$\cdot$ & $\begin{array}{c}601 \\
(485-749)\end{array}$ \\
\hline \multicolumn{6}{|l|}{ Indirect costs } \\
\hline Productivity loss & $34 \cdot 75$ & 34 & $1667 \cdot 65$ & 35 & $1442 \cdot 90$ \\
\hline \multicolumn{6}{|l|}{ Total societal costs } \\
\hline $\begin{array}{l}\text { Total societal costs, } \\
\text { bootstrapped mean }(95 \% \mathrm{Cl})\end{array}$ &.$\cdot$ &.. & $\begin{array}{l}8251 \\
(6990-9690)\end{array}$ &.$\cdot$ & $\begin{array}{l}11803 \\
(10020-13651)\end{array}$ \\
\hline
\end{tabular}

Villalta scores and continued wearing the stockings until the end of the study. Although there was a slightly larger difference in post-thrombotic syndrome between these subgroups than between the entire individualised treatment group compared with the entire standard treatment group, we found slightly more cost savings for the individualised treatment subgroup ( $€ 3850$ compared 


\begin{tabular}{|c|c|c|c|c|c|c|c|}
\hline & Incremental costs, $€$ & $\begin{array}{l}\text { Incremental QALY } \\
\text { EQ-5D Dutch tariff }\end{array}$ & $\begin{array}{l}\text { Incremental QALY } \\
\text { EQ-5D UK tariff }\end{array}$ & $\begin{array}{l}\text { Incremental QALY } \\
\text { SF-6D }\end{array}$ & $\begin{array}{l}\text { Incremental } \\
\text { cost-effectiveness ratio } \\
\text { [incremental net monetary } \\
\text { benefit] with EQ-5D QALY } \\
\text { Dutch tariff, } €^{*}\end{array}$ & $\begin{array}{l}\text { Incremental } \\
\text { cost-effectiveness ratio } \\
\text { [incremental net } \\
\text { monetary benefit] with } \\
\text { EQ-5D QALY UK tariff, } €^{*}\end{array}$ & $\begin{array}{l}\text { Incremental } \\
\text { cost-effectiveness } \\
\text { ratio [incremental } \\
\text { net monetary } \\
\text { benefit] with } \\
\text { SF-6D QALY, } €^{*}\end{array}$ \\
\hline \multicolumn{8}{|l|}{ Base case $\dagger$} \\
\hline Observed mean & -3536 & -0.0115 & 0.0170 & -0.0004 &.. &.. &.. \\
\hline $\begin{array}{l}\text { Bootstrapped } \\
\text { mean }(95 \% \mathrm{Cl})\end{array}$ & $\begin{array}{l}-3552(-5793 \\
\text { to }-1241)\end{array}$ & $\begin{array}{l}-0.0116 \\
(-0.0506 \text { to } 0.0269)\end{array}$ & $\begin{array}{l}0.0172 \\
(-0.0194 \text { to } 0.0530)\end{array}$ & $\begin{array}{l}-0.0006 \\
(-0.0242 \text { to } 0.0229)\end{array}$ & $\begin{array}{l}305 \cdot 992[3205] \\
(502 \text { to } 5741)\end{array}$ & $\begin{array}{l}\text { Dominant [4071] } \\
\text { (1452 to } 6647)\end{array}$ & $\begin{array}{l}6030 \cdot 941[3540] \\
(1174 \text { to } 5953)\end{array}$ \\
\hline \multicolumn{8}{|l|}{ Complete cases } \\
\hline Observed mean & -177 & 0.0167 & 0.0156 & 0.0091 &.. &.. &.. \\
\hline $\begin{array}{l}\text { Bootstrapped } \\
\text { mean }(95 \% \mathrm{Cl})\end{array}$ & $-182(-1055$ to 715$)$ & $\begin{array}{l}0.0167 \\
(-0.0184 \text { to } 0.0458)\end{array}$ & $\begin{array}{l}0.0150 \\
(-0.0187 \text { to } 0.0490)\end{array}$ & $\begin{array}{l}0.0093 \\
(-0.0139 \text { to } 0.0330)\end{array}$ & $\begin{array}{l}\text { Dominant [683] } \\
(-745 \text { to } 2071)\end{array}$ & $\begin{array}{l}\text { Dominant [6323] } \\
\text { (-910 to } 2183)\end{array}$ & $\begin{array}{l}\text { Dominant [469] } \\
\text { (-823 to } 1746)\end{array}$ \\
\hline \multicolumn{8}{|c|}{ Post-hoc analysis: compression vs no compression for subgroup of patients with Villalta score $\leq 4$ at 6 months } \\
\hline Observed mean & -3850 & 0.0054 & 0.0330 & 0.0252 &.. &.. &.. \\
\hline $\begin{array}{l}\text { Bootstrapped } \\
\text { mean }(95 \% \mathrm{Cl})\end{array}$ & $\begin{array}{l}-3850 \\
(-5811 \text { to }-1863)\end{array}$ & $\begin{array}{l}0.0053 \\
(-0.0329 \text { to } 0.0434)\end{array}$ & $\begin{array}{l}0.0331 \\
(-0.0051 \text { to } 0.0674)\end{array}$ & $\begin{array}{l}0.0251 \\
(0.0016 \text { to } 0.0480)\end{array}$ & $\begin{array}{l}\text { Dominant [4010] } \\
\text { (1677 to } 6305)\end{array}$ & $\begin{array}{l}\text { Dominant [4789] } \\
\text { (2568 to } 7085 \text { ) }\end{array}$ & $\begin{array}{l}\text { Dominant [ } 4605] \\
\text { (2478 to } 6772 \text { ) }\end{array}$ \\
\hline
\end{tabular}

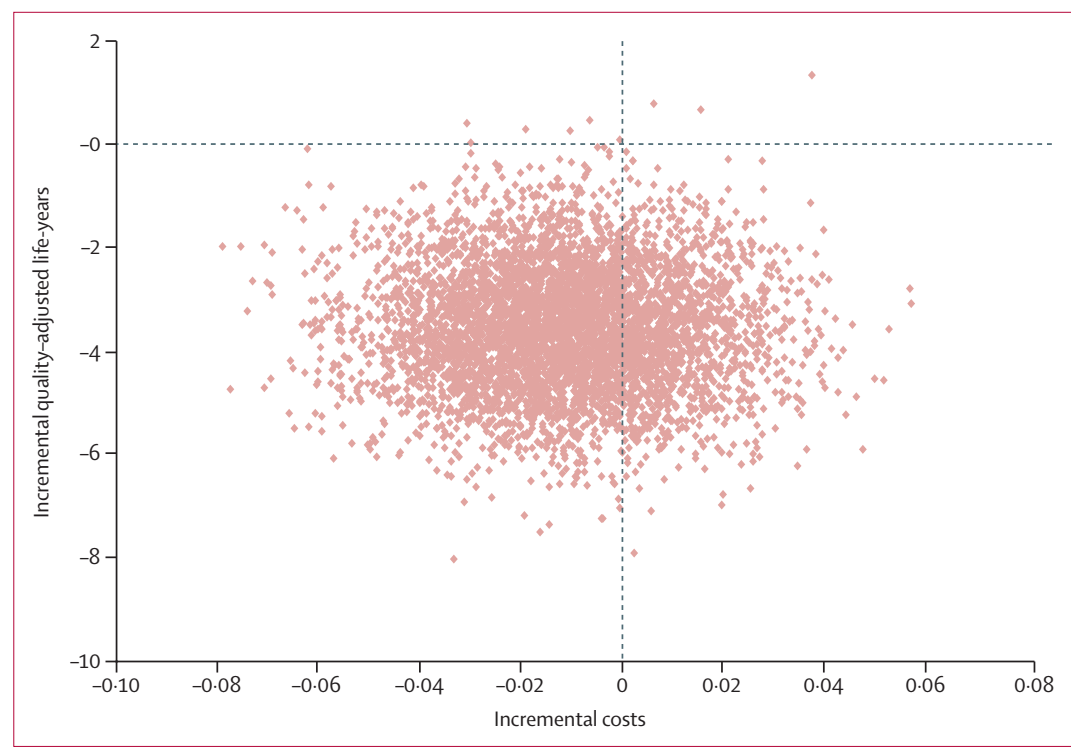

Figure 1: Bootstrapped incremental cost-effectiveness results (based on EQ-5D Dutch tariff) of individualised duration of elastic compression stocking treatment

with $€ 3536$ for the entire population) and a gain in QALYs as compared with the overall population of patients in the IDEAL DVT trial.

\section{Discussion}

To our knowledge, this is the first health economic evaluation of the use of elastic compression therapy for prevention of post-thrombotic syndrome. We specifically directed our analysis at the cost-effectiveness of individualised shortened duration of therapy compared with standard duration of therapy, which is 2 years. ${ }^{7-9}$

Two previous studies have assessed variable duration of elastic compression therapy to prevent post-thrombotic

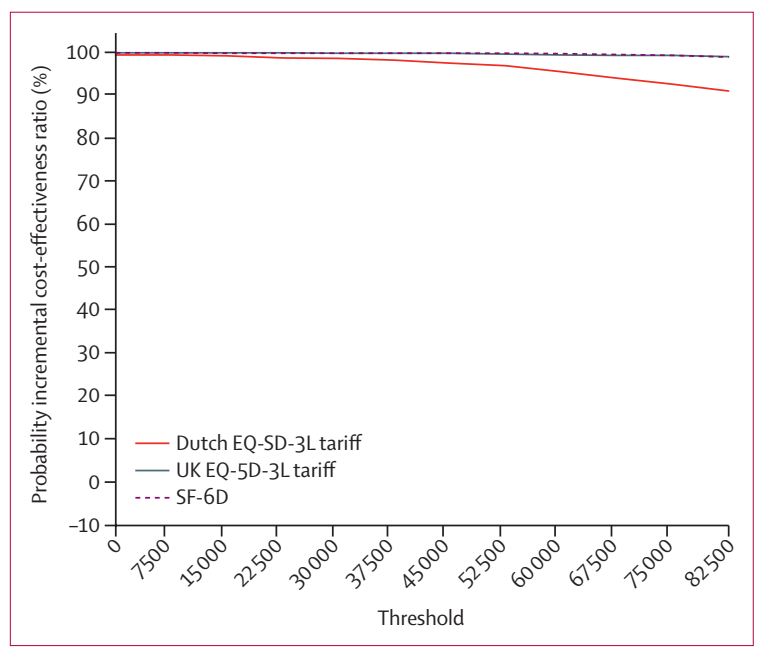

Figure 2: Cost-effectiveness acceptability curves of use of individualised duration of elastic compression stocking treatment versus standard duration of stocking treatment

SF-6D=Short-Form Six-Dimension.

syndrome, ${ }^{16,17}$ but neither assessed the cost-effectiveness of such strategies. Aschwanden and colleagues compared 6 months of treatment with elastic compression therapy versus a prolonged duration of 24 months in patients with newly-diagnosed deep vein thrombosis..$^{16}$ They found that the occurrence of post-thrombotic skin changes, assessed according to the CEAP score, in the group allocated to 6 months of elastic compression therapy did not differ significantly from the group assigned to longterm duration of therapy (hazard ratio $0 \cdot 60,95 \% \mathrm{CI}$ $0 \cdot 28-1 \cdot 28)$. In the OCTAVIA study, ${ }^{17}$ selected patients with Villalta scores of less than 5 and excellent adherence to compression therapy were randomly assigned to standard 24 months of elastic compression therapy versus 
1 year of compression therapy. This trial failed to show non-inferiority for the shortened duration of therapy: the absolute difference in occurrence of post-thrombotic syndrome was $6.9 \%$, with the $95 \%$ CI upper limit of $12.3 \%$ exceeding the predefined non-inferiority margin of $10 \%$. In December, 2017, we reported the primary outcome of the IDEAL DVT study, ${ }^{15}$ which showed that individualised shortened duration of elastic compression therapy for prevention of post-thrombotic syndrome was feasible. We showed that $283(66 \%)$ of 432 patients in the intervention group could stop treatment early, guided by a low Villalta score. We found no significant difference in the proportion of post-thrombotic syndrome after 2 years for those assigned to individualised shortened duration as compared with standard duration of therapy (odds ratio $1.06,95 \% \mathrm{CI}-0.78$ to 1.44 ). We concluded that individualised duration of elastic compression therapy was safe and effective and anticipated that this treatment strategy was likely to reduce health-care costs.

Our results from this analysis show that quality of life as measured by EQ-5D-3L and SF-36 version 2 started increasing 3 months after the thrombotic event, and quality of life did not differ between patients assigned to individualised duration or standard 2-year duration of elastic compression therapy throughout the study. The costs for both treatment groups consisted mainly of healthcare costs due to the high costs of home care. We found individualised duration of elastic compression therapy to be the most cost-effective option, irrespective of the instrument used to obtain utilities to calculate QALYs. In the Netherlands, for 25000 incident cases of deep vein thrombosis per annum, ${ }^{28}$ savings (measured over 2 years) from implementing the individualised strategy would amount to $€ 88$ million ( $95 \%$ CI 31 million to 144 million).

Sensitivity analysis with the complete cases showed individualised duration of elastic compression therapy was more effective and less costly than was treatment with standard duration of compression therapy. In the complete case analysis the cost savings were lower, but overall the individualised strategy was still cost-effective.

On the basis of results from OCTAVIA, ${ }^{17}$ which showed that the incidence of post-thrombotic syndrome was increased in patients with a low Villalta score who stopped elastic compression therapy early, we did a posthoc analysis in a subgroup of patients from the IDEAL DVT trial with a Villalta score of 4 or less until 6 months. This analysis suggested that shorter duration of compression stocking use is also cost-effective in this subpopulation. Therefore, in these patients prolonged treatment might also be forgone.

The data for our economic study had some limitations. First, the number of patients who used some of the categories of care was small. Despite the large number of patients in the IDEAL DVT study population, the trial might therefore have been underpowered for some specific data categories. Nevertheless, the $95 \%$ CI of the incremental costs ranged from $€ 5793$ saved to
$€ 1241$ saved, and the probability that individualised therapy duration was cost-effective was calculated to be $99 \%$. Second, the time window for the economic analysis was limited to the 2-year duration of the study, so longterm consequences for cost-effectiveness are unknown. However, most patients who develop post-thrombotic syndrome are diagnosed with this syndrome within the first 2 years after deep vein thrombosis. ${ }^{29}$ Although the consequences of post-thrombotic syndrome will extend beyond the time limit of our trial, the small difference in incidence of post-thrombotic syndrome at 2 years and the similarities in quality of life between groups shown in this analysis suggest that the likelihood of long-term negative effects on health is small. Third, the IDEAL DVT study design only allowed for shortened duration of compression therapy on the basis of Villalta score results after 6 months of therapy. Whether the duration of compression therapy can be reduced even further, with potential further implications for cost-effectiveness, could be the objective of further studies. Finally, because of the amount of missing data, we had to impute data to prevent a loss of statistical power and to decrease the probability of obtaining biased estimates. We used predictive mean matching (the only method that yields plausible imputations and preserves the original data distributions) $)^{27}$ and the conclusions that we drew from analysis of complete data and imputed data were the same, so we are confident that the outcomes we present are robust. Some of the main strengths of this economic analysis are the large sample size, the low risk of bias because of the randomised nature of the IDEAL DVT trial from which the data were extracted, and the use of three instruments to obtain utilities to calculate QALYs, with consistent results between these calculations.

In conclusion, we showed that individualised duration of elastic compression therapy for prevention of postthrombotic syndrome is a cost-effective strategy compared with the standard 2-year duration of compression stocking use. By using an individualised approach, substantial cost savings can be made, both from a health-care perspective and a societal perspective, without significant loss in health-related quality of life.

Contributors

EEA contributed to data collection, data analysis, data interpretation, and writing of the report. AJtC-H contributed to study concept and design, funding, recruitment of centres, data collection, data analysis, data interpretation, and writing of the report. MHP contributed to study design, funding, and writing and reviewing of the report. HtC contributed to study concept and design, funding, data collection, data interpretation, and writing of the report. MAJ contributed to the study design, funding, data analysis, data interpretation, and writing of the report. All other authors contributed equally to data collection, writing, and reviewing of the report.

\section{Declaration of interests}

We declare no competing interests.

Acknowledgments

The trial was funded by a grant from ZonMw (grant number 171102007), the Netherlands Organisation for Health Research and Development (a government organisation promoting research into cost-effectiveness of medical treatments). 


\section{References}

1 Prandoni P, Kahn SR. Post-thrombotic syndrome: prevalence, prognostication and need for progress. Br J Haematol 2009; 145: 286-95.

2 Kahn SR, Shrier I, Julian JA, et al. Determinants and time course of the postthrombotic syndrome after acute deep venous thrombosis. Ann Intern Med 2008; 149: 698-707.

3 Pesavento R, Villalta S, Prandoni P. The postthrombotic syndrome. Intern Emerg Med 2010; 5: 185-92.

4 Kahn SR, Ducruet T, Lamping DL, et al. Prospective evaluation of health-related quality of life in patients with deep venous thrombosis. Arch Intern Med 2005; 165: 1173-78.

5 Bergqvist D, Jendteg S, Johansen L, Persson U, Odegaard K. Cost of long-term complications of deep venous thrombosis of the lower extremities: an analysis of a defined patient population in Sweden. Ann Intern Med 1997; 126: 454-57.

6 Caprini JA, Botteman MF, Stephens JM, et al. Economic burden of long-term complications of deep vein thrombosis after total hip replacement surgery in the United States. Value Health 2003; 6: 59-74.

7 Brandjes DP, Büller HR, Heijboer H, et al. Randomised trial of effect of compression stockings in patients with symptomatic proximal-vein thrombosis. Lancet 1997; 349: 759-62.

8 Prandoni P, Lensing AW, Prins MH, et al. Below-knee elastic compression stockings to prevent the post-thrombotic syndrome: a randomized, controlled trial. Ann Intern Med 2004; 141: 249-56.

9 Guyatt GH, Akl EA, Crowther M, et al. Executive summary: Antithrombotic therapy and prevention of thrombosis, 9th ed: American College of Chest Physicians Evidence-Based Clinical Practice Guidelines. Chest 2012; 141 (2 suppl): 7S-47S.

10 Appelen D, van Loo E, Prins MH, Neumann MH, Kolbach DN. Compression therapy for prevention of post-thrombotic syndrome. Cochrane Database Syst Rev 2017; 9: CD004174.

11 Ten Cate-Hoek AJ, Bouman AC, Joore MA, Prins M, Ten Cate H. The IDEAL DVT study, individualised duration elastic compression therapy against long-term duration of therapy for the prevention of post-thrombotic syndrome: protocol of a randomised controlled trial. BMJ Open 2014; 4: e005265.

12 Blattler W. Aspects of cost effectiveness in therapy of acute leg/pelvic vein thrombosis. Wien Med Wochenschr 1999; 149: 61-65.

13 Raju S, Hollis K, Neglen P. Use of compression stockings in chronic venous disease: patient compliance and efficacy. Ann Vasc Surg 2007; 21: 790-95.

14 Gelderblom G, Hagedoorn-Meuwissen EAV. Kousen uittrekhulpmiddel Easy-Lever. Een onderzoek naar bruikbaarheid, effecten en belemmeringen. in opdracht van ZonMw. 2005.

15 ten Cate-Hoek AJ, Amin EE, Bouman AC, et al. Individualised versus standard duration of elastic compression therapy for prevention of post-thrombotic syndrome (IDEAL DVT): a multicentre, randomised, single-blind, allocation-concealed, non-inferiority trial. Lancet Haematol 2018; 5: e25-33.
16 Aschwanden M, Jeanneret C, Koller MT, Thalhammer C, Bucher HC, Jaeger KA. Effect of prolonged treatment with compression stockings to prevent post-thrombotic sequelae: a randomized controlled trial. J Vasc Surg 2008; 47: 1015-21.

17 Mol GC, van de Ree MA, Klok FA, et al. One versus two years of elastic compression stockings for prevention of post-thrombotic syndrome (OCTAVIA study): randomised controlled trial. BMJ 2016; 353: i2691.

18 Brooks R. EuroQol: the current state of play. Health Policy 1996; 37: 53-72

19 Ware JE, Snoww K, Kosinski MA, Gandek BG. SF-36® Health Survey Manual and Interpretation Guide. Lincoln, RI: Quality Metric Inc, 1993.

20 Zee van der KL SR. Het meten van de algemene gezondheidstoestand met de RAND-36, een handleiding2012; Tweede herziene druk. https://www.umcg.nl/ SiteCollectionDocuments/research/institutes/SHARE/ assessment\%20tools/handleiding_rand36_2e_druk.pdf (accessed Sept 28, 2018)

21 Dolan P. Modeling valuations for EuroQol health states. Med Care 1997; 35: 1095-108.

22 Lamers LM, Stalmeier PF, McDonnell J, Krabbe PFM, van Busschbach JJ. Measuring the quality of life in economic evaluations: the Dutch EQ-5D tariff. Ned Tijdschr Geneeskd 2005; 149: $1574-78$

23 Brazier JE, Roberts J. The estimation of a preference-based measure of health from the SF-12. Med Care 2004; 42: 851-59.

24 Koopmanschap MA. PRODISQ: a modular questionnaire on productivity and disease for economic evaluation studies. Expert Rev Pharmacoecon Outcomes Res 2005; 5: 23-28.

25 Hakkaart-van Roijen L, van der Linden N, Bouwmans C, Kanters T, Tan SS. Kostenhandleiding. Methodologie van kostenonderzoek en referentieprijzen voor economische evaluaties in de gezondheidszorg. Institute for Medical Technology Assessment Erasmus Universiteit Rotterdam. 2016. https://www. zorginstituutnederland.nl/publicaties/publicatie/2016/02/29/ richtlijn-voor-het-uitvoeren-van-economische-evaluaties-in-degezondheidszorg (accessed Sept 9, 2018).

26 Brouwer WB, Koopmanschap MA. The friction-cost method: replacement for nothing and leisure for free? Pharmacoeconomics 2005; 23: 105-11.

27 Vink G, Frank LE, Pannekoek J, van Buuren S. Predictive mean matching imputation of semicontinuous variables. Stat Neerl 2014; 68: 61-90.

28 Naess IA, Christiansen SC, Romundstad P, Cannegieter SC, Rosendaal FR, Hammerstrøm J. Incidence and mortality of venous thrombosis: a population-based study. J Thromb Haemost 2007; 5: 692-99.

29 Prandoni P, Lensing AW, Cogo A, et al. The long-term clinical course of acute deep venous thrombosis. Ann Intern Med 1996; 125: $1-7$ 